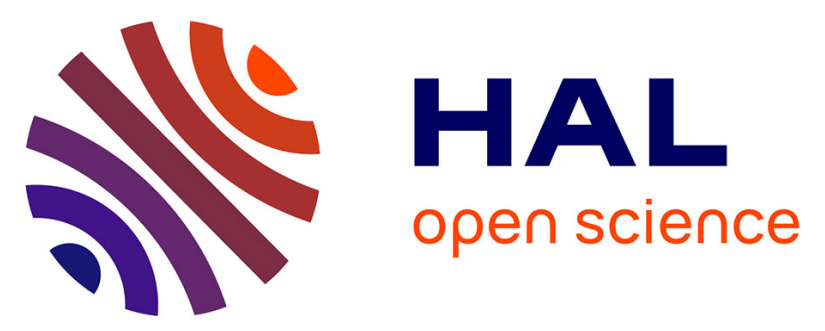

\title{
Deposition pattern of aerosolized Legionella using an ex vivo human-porcine respiratory model
}

Sophie Perinel, Valérie Forest, Mathilde Landraud, Jérémie Pourchez, Françoise Girardot, Serge Riffard, Magalie Stauffert, Jean-Michel Vergnon, Séverine Allegra

\section{To cite this version:}

Sophie Perinel, Valérie Forest, Mathilde Landraud, Jérémie Pourchez, Françoise Girardot, et al.. Deposition pattern of aerosolized Legionella using an ex vivo human-porcine respiratory model. International Journal of Hygiene and Environmental Health, 2018, 221 (2), pp.252-259. 10.1016/j.ijheh.2017.11.002 . hal-01690771

\section{HAL Id: hal-01690771 \\ https://hal.science/hal-01690771}

Submitted on 9 Oct 2018

HAL is a multi-disciplinary open access archive for the deposit and dissemination of scientific research documents, whether they are published or not. The documents may come from teaching and research institutions in France or abroad, or from public or private research centers.
L'archive ouverte pluridisciplinaire HAL, est destinée au dépôt et à la diffusion de documents scientifiques de niveau recherche, publiés ou non, émanant des établissements d'enseignement et de recherche français ou étrangers, des laboratoires publics ou privés. 
Deposition pattern of aerosolized Legionella using an ex vivo human-porcine respiratory model

Sophie Perinel ${ }^{\mathrm{a}}$, Valérie Forest ${ }^{\mathrm{b} *}$, Mathilde Landraud ${ }^{\mathrm{b}, \mathrm{c}}$, Jérémie Pourchez ${ }^{\mathrm{b}}$, Françoise Girardot $^{c}$, Serge Riffard ${ }^{c}$, Magalie Stauffert ${ }^{c}$, Jean-Michel Vergnon $^{\mathrm{a}}$, Séverine Allegra ${ }^{\mathrm{c}}$

${ }^{a}$ Université de Lyon, Université Jean Monnet, INSERM, SainBioSE, F-42023 Saint Etienne, France.

${ }^{\mathrm{b}}$ Université de Lyon, IMT Mines Saint-Etienne, Centre CIS, INSERM, SainBioSE, F-42023 Saint-Etienne, France

${ }^{\mathrm{c}}$ Université de Lyon, Université Jean Monnet, CNRS, EVS-ISTHME UMR 5600, F-42023 Saint-Etienne, France

* Corresponding author: Valérie Forest

École Nationale Supérieure des Mines de Saint-Etienne

158 cours Fauriel, CS 62362

42023 Saint-Etienne Cedex 2. FRANCE.

Email address: vforest@emse.fr - Telephone number: +33477499776 


\section{Abstract}

Legionella are bacteria responsible for severe lung pathologies. However how they enter and are deposited within the respiratory tract remains poorly documented. Data using animal testing led to the establishment of mathematical models allowing the estimation of aerosol dispersion risks. But direct extrapolation to humans is questionable and experimental models more physiologically representative of the inhalation route are welcome. The aim of this study was to develop a model as close as possible to the human anatomy and physiology allowing determining the deposition pattern of aerosolized Legionella while limiting in vivo experiments. To that purpose, we adapted the chimeric respiratory tract model we previously developed. This original model consisted of a replica of the human upper respiratory airways made by additive manufacturing connected to ex vivo porcine lungs ventilated by passive expansion, as for humans in physiological conditions. These experiments didn't imply specific animal sacrifices as pigs were bred for human consumption and lungs were considered as wastes by the slaughterhouse. Fluorescent Legionella were aerosolized and visualized using Cellvizio ${ }^{\circledR}$ Lab (probe-based confocal fluorescence microscope). Legionella were found in the whole respiratory tract. Broncho-alveolar lavages were also performed and the amount of Legionella reaching the thoracic region was quantified by culture and qPCR. Legionella were found preferentially in the left upper lobe compared to the right lower lobe. To our knowledge, it is the first time that experiments mimicking so closely human exposure by inhalation are performed while limiting animal experiments and providing a model for further Legionella infectious risk assessment.

\section{Keywords}

Legionella; lung deposition; aerosolization; broncho-alveolar lavage; ex vivo chimeric model. 


\section{Introduction}

Legionella are Gram-negative bacteria found in various aquatic environments, especially hot water sources including domestic water systems and showers, cooling towers, decorative fountains, hot tubs, etc. (Anses, 2014; Burillo et al., 2017; Khodr et al., 2016; Phin et al., 2014). Legionella are usually spread through water droplets in the air. After inhalation by humans, bacteria are conveyed through the tracheo-bronchial tree deep into the alveoli where they infect macrophages and lung epithelial cells, potentially causing pneumonia called legionellosis including Legionnaires' disease and Pontiac fever (Burillo et al., 2017; Khodr et al., 2016; Phin et al., 2014). Legionella pneumophila, especially from the serogroup 1 (Lpl), is the main species responsible for pathologies (about 90\% of the cases) (Burillo et al., 2017; Khodr et al., 2016; Phin et al., 2014). The incidence of legionellosis is estimated between 8000 and 18000 new cases each year in the United States and between 1200 and 1500 in France (Campèse et al., 2015; WHO, 2016).

The monitoring of Legionella consists of their detection in water samples by culture on selective glycine, vancomycine and polymyxine B charcoal yeast extract (GVPC) agar (quantification as colonies forming units (CFU) per liter, as defined by the AFNOR NF T90431 or ISO 11731-2 standards) or by quantitative PCR (qPCR, as number of genome units (GU) per liter, as defined by the AFNOR NF T90-471 or ISO/TS 12869 standards) (Burillo et al., 2017; Légifrance, 2010). However, it is difficult to correlate the number of detected Legionella to an infectious risk probably due to the presence in the water samples of viable but non-culturable (VBNC) Legionella and to a lesser extent because of PCR and culture inhibitors (Allegra et al., 2008; S. Allegra et al., 2011; Severine Allegra et al., 2011). Regulatory preventive thresholds were established empirically (O’Brien and Bhopal, 1993) based on the observation of legionellosis epidemics when a correlation between patient and environment was possible (less than $16 \%$ of the cases) or based on in vivo studies. The way 
infectious doses are determined depends on the reservoir studied (water or aerosols) and/or on the models used (such as animals). Mathematical models allowing the estimation of aerosol dispersion risks have been described but it is not possible to directly extrapolate their results to humans (Armstrong and Haas, 2008; Thomas W. Armstrong and Haas, 2007; T. W. Armstrong and Haas, 2007). Therefore, adapted models and methodologies are required to improve Legionella detection and quantification to revisit or refine the infectious doses obtained from animal models. Moreover, inhalation of aerosols should be used, more representative of a physiological route than intratracheal or intraperitoneal injections or instillations. As a matter of fact, to date, how Legionella may enter and be deposited in the respiratory tract upon aerosol generation remains poorly documented (Górny et al., 1999; Thomas et al., 2008).

In this context, the aim of the present study was to propose an experimental model, as close as possible to the human anatomy and physiology, allowing determining the deposition pattern of aerosolized Legionella within the respiratory tract. These data are important to determine a real risk of inhalation exposure by the assessment of the infectious dose reaching the respiratory barrier. One of our main concerns to reach this objective was to limit animal experiments in accordance with the 3R concept introduced by Russell and Burch (Russell and Burch, 1959). Indeed, we paid attention to replace, reduce and refine our research approach by developing an alternative and very innovative experimental model. To that purpose, we adapted and optimized a chimeric respiratory model we previously developed and validated for other researches in the aerosol therapy field (Perinel et al., 2017). It consisted of a complete respiratory tract including a 3D replica of the human upper respiratory airways (nasal cavity, pharynx, sinuses) made by additive manufacturing allowing oro-nasal breathing. This human replica was connected to ex vivo porcine lungs through a home-made artificial larynx. It is important to mention that lungs did not come from animals bred for scientific 
research but from animals bred for human consumption. They were provided by a slaughterhouse as in France lungs are not fit for human consumption and are consequently considered as organic wastes. It means that no animals were sacrificed specifically for this study since we used, for scientific research, organic wastes that are currently discarded by slaughterhouse. Lungs were ventilated by passive expansion as in human physiological ventilation allowing to reproduce inhalation exposure to aerosols (El Merhie et al., 2016; Le Guellec et al., 2014; Leclerc et al., 2014a; Perinel et al., 2016, 2017). Previously, characterized Legionella aerosols generated upon nebulization using a fluorescent Legionella strain (Allegra et al., 2016). This strain was aerosolized in the chimeric model as ventilation was ongoing and then visualized using the Cellvizio ${ }^{\circledR}$ Lab technology (probe-based confocal fluorescence microscope). Broncho-alveolar lavages (BAL) were also performed to quantify the amount of Legionella reaching the thoracic region. To our knowledge, it is the first time that experiments mimicking so closely a real human physiological exposure were performed while limiting animal experiments.

\section{Materials and Methods}

\section{Legionella airborne suspensions}

A Legionella pneumophila serogroup 1 (Lpl) species (responsible for LD) was used in this study. Bacteria are fluorescent as they were transfected with a GFP-containing plasmid and thus express the green fluorescent protein (GFP) (Cormack et al., 1996; Köhler et al., 2000). It was provided by Centre National de Référence des Légionelles (CNRL-Lyon) as their 008 strain. In this study, the strain is identified as Lpl-008. Thanks to the GFP, Legionella deposition was followed (Köhler et al., 2000; Unal and Steinert, 2006). Legionella were plated on BCYE agar (Buffered Charcoal Yeast Extract, SR0110C, Oxoid, France) 
supplemented with $8 \mathrm{mg} / \mathrm{mL}$ chloramphenicol (Sigma Aldrich, France) (BCYE+Chl) to select the bacteria bearing the GFP-containing plasmid.

For the nebulization process, suspensions were prepared from Legionella cultivated in $\mathrm{BCYE}+\mathrm{Chl}$ for $72 \mathrm{~h}$ at $37^{\circ} \mathrm{C}$ under a $5 \% \mathrm{CO}_{2}$ atmosphere to get bacteria with similar morphology to pathogenic Legionella present in aquatic reservoirs (Robertson et al., 2014). 8 $\mathrm{mL}$ of calibrated Legionella suspension were prepared in sterile normal saline $(0.9 \% \mathrm{NaCl})$ water at a final concentration of $2 \times 10^{7} \mathrm{CFU} / \mathrm{mL}$. An optical density of 0.2 at $600 \mathrm{~nm}$ (Biomate TM3; Avantec, Illkirch, France) was taken as reference for a bacteria suspension containing $10^{8} \mathrm{CFU} / \mathrm{mL} .5 \mathrm{~mL}$ of this suspension were placed in the nebulizer (see the aerosol generation section below) and aerosolized during lung ventilation.

\section{Experimental model}

A unique chimeric model was previously developed and well characterized (Perinel et al., 2017). It was adapted for this specific research on Legionella bioaerosol exposure by inhalation. As shown by Figure 1, it is composed of a 3D resin replica corresponding to the human upper respiratory airways connected to an ex vivo porcine pulmonary tract placed in a sealed enclosure. It was ventilated artificially by passive expansion, simulating pleural depressions (Super Dimension® ${ }^{\circledR}$, Covidien, Dusseldorf Germany). The anatomical model of the upper respiratory airways includes the entire nasal cavities (nasal fossae, frontal, ethmoid and maxillary sinuses) and the oro-pharynx, allowing an oro-nasal ventilation. It was made by additive manufacturing after a 3D image processing from CT-scan data as described in a previous study (Le Guellec et al., 2014). It was manufactured in transparent water resistant and non-porous resin. Its use was validated for the quantification of aerosol drug deposition in the extra-thoracic regions (El Merhie et al., 2016; Le Guellec et al., 2014; Leclerc et al., 2014a). Thus this part of the model represents the extra-thoracic area and was connected to 
porcine lungs which were provided by a slaughterhouse and used within 24 hours. 6 independent experiments were conducted. Lungs were carefully selected to avoid lesions incompatible with a good functioning of the model and small cuts were fixed by stitches. The artificial laryngeal part was made of plastic tubes with a one-way valve simulating the vocal folds resistance as inhalation was ongoing (El Merhie et al., 2016; Le Guellec et al., 2014; Leclerc et al., 2014a). Another one-way valve allowed the path for exhalation as previously described (Leclerc et al., 2014b). An expiratory filter avoided environmental contamination. Physiological measurements for this model were consistent with the widely accepted human physiology (Perinel et al., 2017). Experimental conditions used were biomimetic with a breathing technological process simulating the intrapleural depressions. Indeed, the chimeric model respired artificially by inflation with a negative pressure (passive expansion) applied inside an instrumented sealed enclosure (Perinel et al., 2017). The inhalation is due to the depression inside the instrumented sealed enclosure and the exhalation is passive by the return to atmospheric pressure by a pause of the depression generator. Moreover the duration of inhalation and exhalation in the respiratory cycle was chosen with shorter time duration for inhalation. In order to fit the human physiology, an inspiratory-to-expiratory time [I/E] ratio of $1 / 2$ meaning $1.3 \mathrm{~s}$ for inhalation and $2.6 \mathrm{~s}$ for exhalation was chosen, leading to a respiratory cycle of $4 \mathrm{~s}$ and consequently a respiratory rate of $15 / \mathrm{min}$. These breathing parameters were selected because they correspond to adult male physiology at rest. The extra-thoracic dead space was $21 \mathrm{~mL}$, the tracheal internal diameter $1.7 \mathrm{~cm}$ and the tracheal length $7.5 \mathrm{~cm}$ (Booker, 2009; Criée et al., 2011; Flesch and Dine, 2012). The chimeric model satisfied the major functional and anatomical features necessary to study airborne particle deposition (Perinel et al., 2017, 2016). A video showing the lung ventilation is provided as supplementary data. 


\section{$\underline{\text { Aerosol generation }}$}

The nebulizer used to aerosolize bacterial suspensions was an e-Flow ${ }^{\circledR}$ Rapid Nebulizer System (PARI GmbH, Stanberg, Germany). The mechanism of aerosol generation was based on a perforated oscillating membrane technology. It consists of the high-frequency vibration of a very thin membrane provided with a multitude of micrometric holes in order to obtain a very fine nebulization through the holes from the liquid contained in the device reservoir (Thomas et al., 2008). The main advantages of vibrating-mesh nebulizers include consistent aerosol generation efficiency, a high fine particle fraction reaching the peripheral lung and a low residual volume in the reservoir. In addition, inhaled fractions are more important with mesh nebulizers than with jet nebulizers and can provide higher drug doses to patients (Ari, 2014). To secure the experimenters and prevent them from inhaling Legionella during nebulization, the model was placed in a glove box (815-PGB "LA PETITE" GLOVE BOX, Fisher Scientific). Moreover, BCYE agar Petri dishes were placed outside and inside the glove box to evaluate air contamination.

\section{$\underline{\text { Broncho-alveolar lavages }}$}

Broncho-alveolar lavages were performed after Legionella nebulization in the left upper lobe and right lower lobe with $200 \mathrm{~mL}$ of sterile normal saline $(0.9 \% \mathrm{NaCl})$ water $(6.5<\mathrm{pH}<7.1)$ for each area according to international guidelines (Luyt and Chastre, 2010). Ventilation was ongoing during the whole process. The recovered volumes of BAL were slightly different between the assays. In order to compare comparable things, this volume was taken into account in our calculations and the amount of Legionella was finally expressed as CFU/mL of BALF.

\section{Broncho-alveolar lavage fluids analysis}


The quantitative assessment of Legionella in broncho-alveolar lavage fluids (BALF) was carried out by culture and qPCR for the 6 experiments. For culture, each initial bacterial suspensions $(100 \mu \mathrm{L})$ and BALF $(500 \mu \mathrm{L})$ were plated on two BCYE agar supplemented with or without chloramphenicol and incubated at $37^{\circ} \mathrm{C}$ for $72 \mathrm{~h}$ under a $5 \% \mathrm{CO}_{2}$ atmosphere. All BCYE plates were observed under UV at $366 \mathrm{~nm}$ to identify and enumerate Legionella colonies (CFU) expressing GFP. For qPCR, the quantification was made as described in our previous study (Allegra et al., 2016). Briefly, after a centrifugation at $8000 \mathrm{rpm}$ for $10 \mathrm{~min}$ of a $1 \mathrm{~mL}$ sample (initial bacterial suspension or BALF), plasmid DNA was extracted (NuCleoSpin ${ }^{\circledR}$ Plasmid kit, Macherey-Nagel). qPCR was carried out on a StepOne automate (ThermoFisher Scientific), using the $2 \mathrm{X}$ Power SYBR® Green PCR Master Mix (Life Technologies) as follows: initial denaturation for $15 \mathrm{~min}$ and a two-step cycle consisting of 15 s denaturation, $1 \mathrm{~min}$ annealing and elongation at $60^{\circ} \mathrm{C}$. After 45 cycles of amplification, a melting curve program was incorporated to check for any primer dimers or other non-specific amplifications. Each sample was run in duplicate. A standard curve was done with Lp1-008 initial suspensions ranging from $2 \times 10^{7}$ to $2 \times 10^{2} \mathrm{CFU} / \mathrm{mL}$ to allow the $\mathrm{qPCR}$ results expression in CFU (3 independent experiments were carried out). The results were analyzed using StepOne Software v2.3.

\section{Visualization of deposited Legionella by probe-based confocal fluorescence microscope}

Because the bacteria are transformed with a GFP-containing plasmid, Legionella reaching the intra-thoracic region can be visualized using the Cellvizio ${ }^{\circledR}$ Lab (Mauna Kea Technologies). This probe-based confocal fluorescence microscope technology allows the detection of Legionella on tissue biopsies with a cellular resolution. To assess the presence of fluorescent bacteria and potentially identify areas of privileged deposition, biopsies were performed in the 
trachea, left lower lobe, right upper lobe and middle lobe. The fluorescence (excitation wavelength $=488 \mathrm{~nm}$ ) was then determined in each biopsy sample.

\section{Results}

\section{Aerodynamic characterization of the Legionella bioaerosol}

Aerosols containing Legionella generated upon nebulization were previously extensively characterized (Allegra et al., 2016). It was determined that the distribution of airborne Legionella showed a Mass Median Aerodynamic Diameter (MMAD) of $3.4 \pm 0.4 \mu \mathrm{m}$ with a Geometric Standard Deviation (GSD) of $4.1 \pm 1.2 \mu \mathrm{m}$. It was also evidenced that $0.26-2.5 \mu \mathrm{m}$ aerosol size range represented $7 \%$ of the initial bacterial suspension and among the viable forms, $0.7 \%$ of initial viable bacterial suspension could reach the lung alveoli.

\section{Qualitative assessment of airborne Legionella deposition in the thoracic region}

After nebulization of fluorescent Legionella, biopsies were performed in various areas of the tracheo-bronchial tree (see Figure 2) and the tissue fluorescence was analyzed using the Cellvizio ${ }^{\circledR}$ Lab technology. The detection was made easier by the fact that porcine lungs, contrary to human lungs, are not auto-fluorescent at the excitation wavelength used. Thus no background noise was recorded and the fluorescence observed necessarily came from Legionella, rendering the signal very specific. Indeed we previously verified in control porcine lungs not submitted to Legionella aerosolization that no fluorescent signal was observed. As shown by Figure 2, Legionella were found in the whole respiratory tract, i.e. fluorescence was detected in the 5 analyzed stages of the tracheo-bronchial tree. In other words, after inhalation Legionella were able to reach the deepest lung structures.

\section{Quantitative assessment of airborne Legionella deposition in the thoracic region}


Broncho-alveolar lavages were performed in the left upper lobe and right lower lobe. Legionella were then quantified in BALF by culture and qPCR. Six independent experiments were performed. Figure 3 shows representative results obtained by culture analysis from experiment 4. BCYE+Chl agar plates were used to select Legionella among the important bacteria of the porcine mucosal flora (Figure $3 \mathrm{C}$ and $\mathrm{D}$ ). Due to a very important porcine lung bacterial flora in experiment 2, no culture results were obtained for this experiment, even on BCYE+Chl agar plates. As expected, results of culture and qPCR showed no significant difference for the enumeration of Legionella in the initial suspensions aerosolized in the 6 experiments i.e. a median \pm standard deviation of $2.9 \times 10^{7} \pm 0.8 \times 10^{7} \mathrm{CFU} / \mathrm{mL}$ for culture and $2.8 \times 10^{7} \pm 0.6 \times 10^{7} \mathrm{CFU} / \mathrm{mL}$ for qPCR. Due to the important inhibition of Legionella growth on $\mathrm{BCYE}+\mathrm{Chl}$ by porcine lung microflora, only $\mathrm{qPCR}$ results were taken into account and shown in Figure 4. A higher concentration of Legionella was systematically enumerated in BALF recovered from the left upper lobe than from the right lower lobe.

\section{Discussion}

To the best of our knowledge, it is the first time that an experimental model mimicking so closely human physiological exposure by inhalation is successfully reported, showing the regional distribution of airborne Legionella in the respiratory tract. Indeed, the qualitative and quantitative assessments of the presence of Legionella bacteria in the different lobes of the lungs and in the bronchial tree are possible using a convenient ex vivo model. Moreover, opposite to previous thought and theoretical data, we found a differential quantification of Legionella between lobes.

We developed this model with the objective to fill a gap in the existing experimental respiratory models to better understand the aerosol route of infection during legionellosis. Indeed, since its description in the late 1970s many studies have attempted to better 
understand the Legionnaires' Disease (LD). To that purpose, in vitro assays and experimental animal models were developed to investigate the pathology mechanisms and to evaluate treatments (Baskerville et al., 1981).

In vitro models represent the simplest models to study the LD. They can be used for mechanistic studies, to study the bacteria/host interactions or to compare the virulence of different bacterial strains. Cells can be either of animal or human origin. The main advantages of in vitro models are their low cost and the easy supply of large quantities of cells. Although basic, cellular models can be useful as shown by Yan and Cirillo (Yan and Cirillo, 2004).

In vivo studies on primitive organisms were also performed as alternative experimental models of LD. For instance the soil amoeba Dictyostelium discoideum (Hägele et al., 2000) or the nematode Caenorhabditis elegans (Brassinga and Sifri, 2013; Komura et al., 2010) were found to be simple hosts suitable to study host/bacteria interactions, intracellular pathogenesis of Legionella, contribution of specific genes to the bacterial virulence and host immunity and apoptosis. Although these alternative approaches could indeed provide useful data at a cellular resolution, they are obviously far from a model allowing extrapolation to Legionella inhalation in humans. For this purpose, other animal models were developed.

A variety of species can be experimentally infected with Legionella such as guinea pigs, mice, rats, monkeys, etc. (Edelstein, 1999). Thus several animal-based infection models of LD have been developed. Nevertheless, guinea pigs were found to be extremely susceptible to Legionella infection and are therefore widely used to produce a disease that simulates human LD in immunocompromised patients (Baskerville et al., 1981; Davis et al., 1982; Edelstein, 1999; Fitzgeorge et al., 1983). However, due to the lack of dedicated reagents to study the immune response to Legionella infection in guinea pigs, this model of infection can hardly be used to monitor the disease. Consequently, research on the molecular and cellular aspects of the antibacterial immune response has shifted to mouse infection models (Brown et al., 2013). 
And indeed, the mouse model of Legionella infection has provided many insights into innate immunity and proved to be a valuable system to elucidate the contribution of inflammatory factors and different immune cells to lung defense (Brown et al., 2013). In addition, mice models have the advantages of being inexpensive, convenient to handle and to generally well tolerate antimicrobial therapy (Rouse and Steckelberg, 1999).

Regarding the infection route, different pathways have been assessed and successfully used to produce Legionella pneumonia in experimental animal models: first intratracheal, intranasal, intraperitoneal and more recently via aerosols inhalation (Leggett, 1999). The issue of exposure is not trivial as it may have different consequences. For instance, Fitzgeorge et al. (Fitzgeorge et al., 1983) demonstrated that infection of guinea pigs by intranasal instillation of two strains of L. pneumophila did not induce disease while the same preparations administered as an aerosol produced a fatal widespread bronchopneumonia within 3 days. The most obvious difference between these exposure routes was the size of the infective particles and their site of deposition within the respiratory tract. Similarly, aerosol inhalation and intratracheal instillations could be used to establish fatal infection in guinea pigs and less severe infection in rats (Edelstein, 1999). The intraperitoneal inoculation seems the less relevant way as, in guinea pigs, it produces peritonitis, systemic infection, sepsis and bacteremic pneumonia so, while easy to produce, it is not a good model for LD (Edelstein, 1999). On the contrary, infection by aerosol inhalation appears to be a successful and reproducible experimental system for the study of $\mathrm{LD}$, and it is particularly relevant to the human disease (Baskerville et al., 1981). For living animals, Legionella bioaerosols can be administered via nose-only or whole body exposure systems.

However, while the animal-based models of LD provide considerable benefits in improving our understanding of Legionella-induced pneumonia and disease pathogenesis, they have some limitations. The different susceptibility to Legionella between species has already been 
mentioned and, as another example, Davis et al. showed that after exposure to a Legionellacontaining aerosol, guinea pigs demonstrated illness, fever and 56\% mortality, whereas rats showed little illness and $11 \%$ mortality (Davis et al., 1982). Another important issue regarding the study of treatment efficacy is that pharmacokinetics of antimicrobial agents given to guinea pigs do not mimic the human situation. In most cases, drug half-lives are shorter in guinea pigs (Burillo et al., 2017; Edelstein, 1999). Similarly, some exposure routes are not relevant with respect to what happens in real life. In this context exposure to aerosols seems the most appropriate but it may exhibit technical constraints, for instance Davis et al. exposed guinea pigs and rats to a nose-only inhalation system for 30 minutes (Davis et al., 1982). This exposure time is quite long and can be stressful for animals.

This is why we propose here a complementary approach consisting of an experimental model with the objective of limiting animal testing while deepening our knowledge of Legionella infections using the inhalation route, as in physiological conditions.

The aim of this study was to propose a first proof of concept using this original model allowing determining the deposition pattern of Legionella bioaerosol in the respiratory tract. To mimic as closely as possible physiological conditions, we adapted a model we previously developed for aerosol therapy purposes (Perinel et al., 2017). In its first version the model included a plastinated head allowing only nasal ventilation. It was replaced here by a resin replica made by additive manufacturing. This latter allowed a mouth-nose ventilation, thus improving the representation of the physiological spontaneous ventilation in adults.

The major advantage of this model is that it does not imply specific animal sacrifices, respecting the $3 \mathrm{R}$ rule and consequently does not raise ethical issues. Indeed, the pigs were dedicated to human consumption and as lungs are considered as wastes they were kindly provided by the slaughterhouse. It implies two other important advantages: an important availability and an inexpensive model. Because the animals are dedicated to human 
consumption, all the sanitary controls were performed at the slaughterhouse in strict accordance with the French regulation. These controls, carried out in presence of veterinary inspectors, guarantee that animals were healthy.

The model and the experimental setting developed were secure as no contamination was observed (no bacterial growth in the Petri dishes placed outside and inside the glove box). Besides its safety, this model proved to be efficient. Indeed, it allowed us to determine that airborne Legionella were able to reach the whole respiratory tract and were found in all the stages of the tracheo-bronchial tree.

The inhibition of Legionella growth on plate by lung microbiota was to be expected. Indeed the difficulty to grow Legionella on agar media has already been described (Hussong et al., 1987; Lück et al., 2004). It is related to the relatively long time of Legionella division compared to other bacteria species, these latter grow faster and fill all the space on the plate. Another explanatory factor is that Legionella enter a viable but not-culturable (VBNC) state. This inhibition is also observed in the clinical analysis of human respiratory samples. The other bacteria present in the porcine lungs do not affect Legionella deposition and viability more than bacteria from the human respiratory mucosa.

We also observed a difference between the deposition of Legionella in the right lower lobe and the left upper lobe. From there, two assumptions could be made to explain this observation: a ventilation gradient between upper and lower zones or an asymmetry of ventilation between left and right lungs. Based on the literature, we can reasonably exclude the first hypothesis. Indeed, it has been demonstrated (West and Dollery, 1960) that this gradient is accurate in upright position (due to the gravity) but it disappears in the supine position in favor of an anterior-posterior gradient (Kaushik et al., 2013). Consequently it is very unlikely to explain this difference in Legionella deposition by physiology in our experimental model. The second hypothesis could be an asymmetry of ventilation between 
left and right lungs. Such observation can be made in humans but it has been linked to the increase in density of the left lung due to the heart (Tawhai et al., 2009). Therefore it cannot be an explanation with our model where the heart was removed before the experimentation. Moreover, a fiberoptic endoscopy was performed before the experiments and did not show any obstruction suggesting homogeneous bronchial tree and no airway obstruction between the right and the left lungs. Further studies are necessary but if they confirm this specific and differential deposition pattern of aerosolized Legionella in lungs, it could be of great interest as, to our knowledge, it is the first time such results are reported. It was quite unexpected and all the more surprising given that in humans the LD is thought to affect the lobes without distinction (Mittal et al., 2017).

It is difficult to further compare our results with those from the literature as, to the best of our knowledge, no such comparable studies were reported. Indeed, we propose an original and innovative model which appears as complementary to previous works.

For the development of further complementary studies we should be aware of the model limitations. First, the model is placed in horizontal position, it does not reproduce the gravity effect human lungs are subjected to. Therefore, the distribution of inhaled bacteria in the lungs may be slightly modified. This horizontal placement is due to technical constraints: in order to protect the experimenters, the experimental system had to be placed under a glove box. However, despite this "non physiological" position, we observed, as discussed before, a differential Legionella deposition between the right lower lobe and the left upper lobe which is consequently not linked to gravity effect.

Despite our efforts to reproduce a model as close as possible to the human anatomy and physiology some factors couldn't be taken into account in these first sets of experiments. For instance the nasal and bronchial mucosa, the ciliated cells, the secretion of mucus/surfactant 
and the body temperature were not reproduced. Nevertheless, we will consider future developments and refinements of the model over time.

We also observed variability in the results. For example, in one case out of the 6 experiments conducted, we noted a lung contamination by the porcine bacterial flora. This is likely due to the fact that pigs can inhale gastric fluids at the time of slaughter (despite the fast for 48 hours before slaughter). This rare event is also possible in humans, for instance in unconscious people or in case of swallowing troubles.

Too few experiments were carried out to draw firm conclusions on the potential infectious dose of Legionella reaching the respiratory tract. But this was beyond the scope of the present study. The first objective of this work was to assess the appropriateness of the model for that kind of research and the feasibility of the techniques. Nevertheless, this preliminary study allowed us to observe that airborne bacteria were viable as it was possible to grow them. So we have a valid model, potentially suitable for Legionella infections studies. But caution should be used and if we actually demonstrated the deposition of Legionella in the tracheobronchial tree, their in situ infectious potential remains to be further examined and characterized.

\section{Conclusions}

Despite these limitations, we were able to establish a new model respecting the $3 \mathrm{R}$ rule, easy to handle and with physiological similarities to human ventilation. This model allowed us to show that aerosolized Legionella were able to reach the deepest structures of the respiratory tract, we were also able to quantify them in different regions. In conclusion, this study is an interesting proof of concept of a new model and from this starting point and preliminary assays, studies will be designed to exploit this model and further investigate the dose/infection issue in the context of a Legionella infection. 


\section{Acknowledgements}

The authors would like to acknowledge Université Jean Monnet (APR UJM) for the financial support. The Despinasse Viande society (La Talaudière, France) is thanked for providing the porcine respiratory tracts.

\section{Conflicts of interest}

None.

\section{References}

Allegra, S., Berger, F., Berthelot, P., Grattard, F., Pozzetto, B., Riffard, S., 2008. Use of flow cytometry to monitor Legionella viability. Appl. Environ. Microbiol. 74, 7813-7816.

Allegra, S., Girardot, F., Grattard, F., Berthelot, P., Helbig, J.H., Pozzetto, B., Riffard, S., 2011. Evaluation of an immunomagnetic separation assay in combination with cultivation to improve Legionella pneumophila serogroup 1 recovery from environmental samples. J. Appl. Microbiol. 110, 952-961.

Allegra, Severine, Grattard, F., Girardot, F., Riffard, S., Pozzetto, B., Berthelot, P., 2011. Longitudinal evaluation of the efficacy of heat treatment procedures against Legionella spp. in hospital water systems by using a flow cytometric assay. Appl. Environ. Microbiol. 77, 1268-1275.

Allegra, S., Leclerc, L., Massard, P.A., Girardot, F., Riffard, S., Pourchez, J., 2016. Characterization of aerosols containing Legionella generated upon nebulization. Sci. Rep. 6, 33998. 
Anses, 2014. Légionelles et légionellose | Anses - Agence nationale de sécurité sanitaire de l'alimentation, de l'environnement et du travail [WWW Document]. URL https://www.anses.fr/fr/content/1\%C3\%A9gionelles-et-1\%C3\%A9gionellose

Ari, A., 2014. Jet, Ultrasonic, and Mesh Nebulizers: An Evaluation of Nebulizers for Better Clinical Outcomes. Eurasian J. Pulmonol. 16, 1-7.

Armstrong, T.W., Haas, C.N., 2008. Legionnaires' disease: evaluation of a quantitative microbial risk assessment model. J. Water Health 6, 149-166.

Armstrong, Thomas W., Haas, C.N., 2007. Quantitative microbial risk assessment model for Legionnaires' disease: assessment of human exposures for selected spa outbreaks. J. Occup. Environ. Hyg. 4, 634-646.

Armstrong, T. W., Haas, C.N., 2007. A quantitative microbial risk assessment model for Legionnaires' disease: animal model selection and dose-response modeling. Risk Anal. Off. Publ. Soc. Risk Anal. 27, 1581-1596.

Baskerville, A., Fitzgeorge, R.B., Broster, M., Hambleton, P., Dennis, P.J., 1981. Experimental transmission of legionnaires' disease by exposure to aerosols of Legionella pneumophila. Lancet Lond. Engl. 2, 1389-1390.

Booker, R., 2009. Interpretation and evaluation of pulmonary function tests. Nurs. Stand. R. Coll. Nurs. G. B. 1987 23, 46-56; quiz 58.

Brassinga, A.K.C., Sifri, C.D., 2013. The Caenorhabditis elegans model of Legionella infection. Methods Mol. Biol. Clifton NJ 954, 439-461.

Brown, A.S., van Driel, I.R., Hartland, E.L., 2013. Mouse models of Legionnaires' disease. Curr. Top. Microbiol. Immunol. 376, 271-291.

Burillo, A., Pedro-Botet, M.L., Bouza, E., 2017. Microbiology and Epidemiology of Legionnaire's Disease. Infect. Dis. Clin. North Am., Legionnaire's Disease 31, 7-27. 
Campèse, C., Descours, G., Lepoutre, A., Beraud, L., Maine, C., Che, D., Jarraud, S., 2015. Legionnaires' disease in France. Médecine Mal. Infect. 45, 65-71.

Cormack, B.P., Valdivia, R.H., Falkow, S., 1996. FACS-optimized mutants of the green fluorescent protein (GFP). Gene 173, 33-38.

Criée, C.P., Sorichter, S., Smith, H.J., Kardos, P., Merget, R., Heise, D., Berdel, D., Köhler, D., Magnussen, H., Marek, W., Mitfessel, H., Rasche, K., Rolke, M., Worth, H., Jörres, R.A., Working Group for Body Plethysmography of the German Society for Pneumology and Respiratory Care, 2011. Body plethysmography--its principles and clinical use. Respir. Med. 105, 959-971.

Davis, G.S., Winn, W.C., Gump, D.W., Craighead, J.E., Beaty, H.N., 1982. Legionnaires' pneumonia after aerosol exposure in guinea pigs and rats. Am. Rev. Respir. Dis. 126, $1050-1057$.

Edelstein, P.H., 1999. Chapter 34 - The Guinea-pig Model of Legionnaires’ Disease, in: Zak, O., Sande, M.A. (Eds.), Handbook of Animal Models of Infection. Academic Press, London, pp. 303-314.

El Merhie, A., Navarro, L., Delavenne, X., Leclerc, L., Pourchez, J., 2016. A new Strategy to Improve Drug Delivery to the Maxillary Sinuses: The Frequency Sweep Acoustic Airflow. Pharm. Res. 33, 1074-1084.

Fitzgeorge, R.B., Baskerville, A., Broster, M., Hambleton, P., Dennis, P.J., 1983. Aerosol infection of animals with strains of Legionella pneumophila of different virulence: comparison with intraperitoneal and intranasal routes of infection. J. Hyg. (Lond.) 90, 81-89.

Flesch, J.D., Dine, C.J., 2012. Lung volumes: measurement, clinical use, and coding. Chest 142, 506-510. 
Górny, R.L., Dutkiewicz, J., Krysińska-Traczyk, E., 1999. Size distribution of bacterial and fungal bioaerosols in indoor air. Ann. Agric. Environ. Med. AAEM 6, 105-113.

Hägele, S., Köhler, R., Merkert, H., Schleicher, M., Hacker, J., Steinert, M., 2000. Dictyostelium discoideum: a new host model system for intracellular pathogens of the genus Legionella. Cell. Microbiol. 2, 165-171.

Hussong, D., Colwell, R.R., O’Brien, M., Weiss, E., Pearson, A.D., Weiner, R.M., Burge, W.D., 1987. Viable Legionella pneumophila Not Detectable by Culture on Agar Media. Nat. Biotechnol. 5, 947-950.

Kaushik, S.S., Freeman, M.S., Cleveland, Z.I., Davies, J., Stiles, J., Virgincar, R.S., Robertson, S.H., He, M., Kelly, K.T., Foster, W.M., McAdams, H.P., Driehuys, B., 2013. Probing the regional distribution of pulmonary gas exchange through singlebreath gas- and dissolved-phase 129Xe MR imaging. J. Appl. Physiol. Bethesda Md $1985115,850-860$.

Khodr, A., Kay, E., Gomez-Valero, L., Ginevra, C., Doublet, P., Buchrieser, C., Jarraud, S., 2016. Molecular epidemiology, phylogeny and evolution of Legionella. Infect. Genet. Evol. J. Mol. Epidemiol. Evol. Genet. Infect. Dis. 43, 108-122.

Köhler, R., Bubert, A., Goebel, W., Steinert, M., Hacker, J., Bubert, B., 2000. Expression and use of the green fluorescent protein as a reporter system in Legionella pneumophila. Mol. Gen. Genet. MGG 262, 1060-1069.

Komura, T., Yasui, C., Miyamoto, H., Nishikawa, Y., 2010. Caenorhabditis elegans as an alternative model host for legionella pneumophila, and protective effects of Bifidobacterium infantis. Appl. Environ. Microbiol. 76, 4105-4108.

Le Guellec, S., Le Pennec, D., Gatier, S., Leclerc, L., Cabrera, M., Pourchez, J., Diot, P., Reychler, G., Pitance, L., Durand, M., Jamar, F., Vecellio, L., 2014. Validation of 
anatomical models to study aerosol deposition in human nasal cavities. Pharm. Res. $31,228-237$.

Leclerc, L., Pourchez, J., Aubert, G., Leguellec, S., Vecellio, L., Cottier, M., Durand, M., 2014a. Impact of airborne particle size, acoustic airflow and breathing pattern on delivery of nebulized antibiotic into the maxillary sinuses using a realistic human nasal replica. Pharm. Res. 31, 2335-2343.

Leclerc, L., Pourchez, J., Prevot, N., Vecellio, L., Le Guellec, S., Cottier, M., Durand, M., 2014b. Assessing sinus aerosol deposition: benefits of SPECT-CT imaging. Int. J. Pharm. 462, 135-141.

Leggett, J., 1999. Chapter 63 - Murine Models of Pneumonia Using Aerosol Inoculation, in: Zak, O., Sande, M.A. (Eds.), Handbook of Animal Models of Infection. Academic Press, London, pp. 533-537.

Légifrance, 2010. Arrêté du 1er février 2010 relatif à la surveillance des légionelles dans les installations de production, de stockage et de distribution d'eau chaude sanitaire.

Lück, P.C., Igel, L., Helbig, J.H., Kuhlisch, E., Jatzwauk, L., 2004. Comparison of commercially available media for the recovery of Legionella species. Int. J. Hyg. Environ. Health 207, 589-593.

Luyt, C.-E., Chastre, J., 2010. Fibreoptic bronchoscopic techniques for diagnosing pneumonia, in: Eur Respir Monogr. pp. 297-306.

Mittal, S., Singh, A.P., Gold, M., Leung, A.N., Haramati, L.B., Katz, D.S., 2017. Thoracic Imaging Features of Legionnaire's Disease. Infect. Dis. Clin. North Am., Legionnaire's Disease 31, 43-54.

O’Brien, S.J., Bhopal, R.S., 1993. Legionnaires' disease: the infective dose paradox. Lancet $342,5-6$. 
Perinel, S., Leclerc, L., Prévôt, N., Deville, A., Cottier, M., Durand, M., Vergnon, J.-M., Pourchez, J., 2016. Micron-sized and submicron-sized aerosol deposition in a new ex vivo preclinical model. Respir. Res. 17, 78.

Perinel, S., Pourchez, J., Leclerc, L., Avet, J., Durand, M., Prévôt, N., Cottier, M., Vergnon, J.M., 2017. Development of an ex vivo human-porcine respiratory model for preclinical studies. Sci. Rep. 7, 43121.

Phin, N., Parry-Ford, F., Harrison, T., Stagg, H.R., Zhang, N., Kumar, K., Lortholary, O., Zumla, A., Abubakar, I., 2014. Epidemiology and clinical management of Legionnaires' disease. Lancet Infect. Dis. 14, 1011-1021.

Robertson, P., Abdelhady, H., Garduño, R.A., 2014. The many forms of a pleomorphic bacterial pathogen-the developmental network of Legionella pneumophila. Front. Microbiol. 5, 670 .

Rouse, M., Steckelberg, J.M., 1999. Chapter 58 - Animal Models of Gram-negative Bacillary Experimental Pneumonia, in: Zak, O., Sande, M.A. (Eds.), Handbook of Animal Models of Infection. Academic Press, London, pp. 495-500.

Russell, W.M.., Burch, R.., 1959. The Principles of Humane Experimental Technique. Methuen.

Tawhai, M.H., Nash, M.P., Lin, C.-L., Hoffman, E.A., 2009. Supine and prone differences in regional lung density and pleural pressure gradients in the human lung with constant shape. J. Appl. Physiol. Bethesda Md 1985 107, 912-920.

Thomas, R.J., Webber, D., Sellors, W., Collinge, A., Frost, A., Stagg, A.J., Bailey, S.C., Jayasekera, P.N., Taylor, R.R., Eley, S., Titball, R.W., 2008. Characterization and deposition of respirable large- and small-particle bioaerosols. Appl. Environ. Microbiol. 74, 6437-6443. 
Unal, C., Steinert, M., 2006. Dictyostelium discoideum as a model to study host-pathogen interactions. Methods Mol. Biol. Clifton NJ 346, 507-515.

West, J.B., Dollery, C.T., 1960. Distribution of blood flow and ventilation-perfusion ratio in the lung, measured with radioactive carbon dioxide. J. Appl. Physiol. 15, 405-410.

WHO, 2016. Legionellosis [WWW Document]. World Health Organ. URL http://www.who.int/mediacentre/factsheets/fs285/en/

Yan, L., Cirillo, J.D., 2004. Infection of murine macrophage cell lines by Legionella pneumophila. FEMS Microbiol. Lett. 230, 147-152. 


\section{Figure captions}

Figure 1 - Illustration of the experimental setting. In the inset, enlargement of the upper respiratory airways replica.

Figure 2 - Deposition pattern of fluorescent Legionella within the indicated areas of the tracheo-bronchial tree. Tissue fluorescence was detected with the Cellvizio ${ }^{\circledR}$ Lab technology. As a negative control the fluorescence in the lung parenchyma was assessed before exposure to Legionella.

Figure 3 - Representative culture results from experiment 4. A) Legionella colonies of aerosolized suspension. B) Experimental air room contamination during experiment. C, D) Cultures from BALF from the lower right and upper left lobes respectively. The number of Legionella was determined by counting the number of green fluorescent colonies under UV light. Legionella growth was inhibited by the bacteria present in porcine lung.

Figure 4 - Median levels of Legionella number (CFU/mL, black dash) found in BALF from the right lower lobe and the left upper lobe as determined by qPCR (n=6). The minimal and maximal values (grey dashes) as well as the first and third quartiles are also represented. 
Figure 1

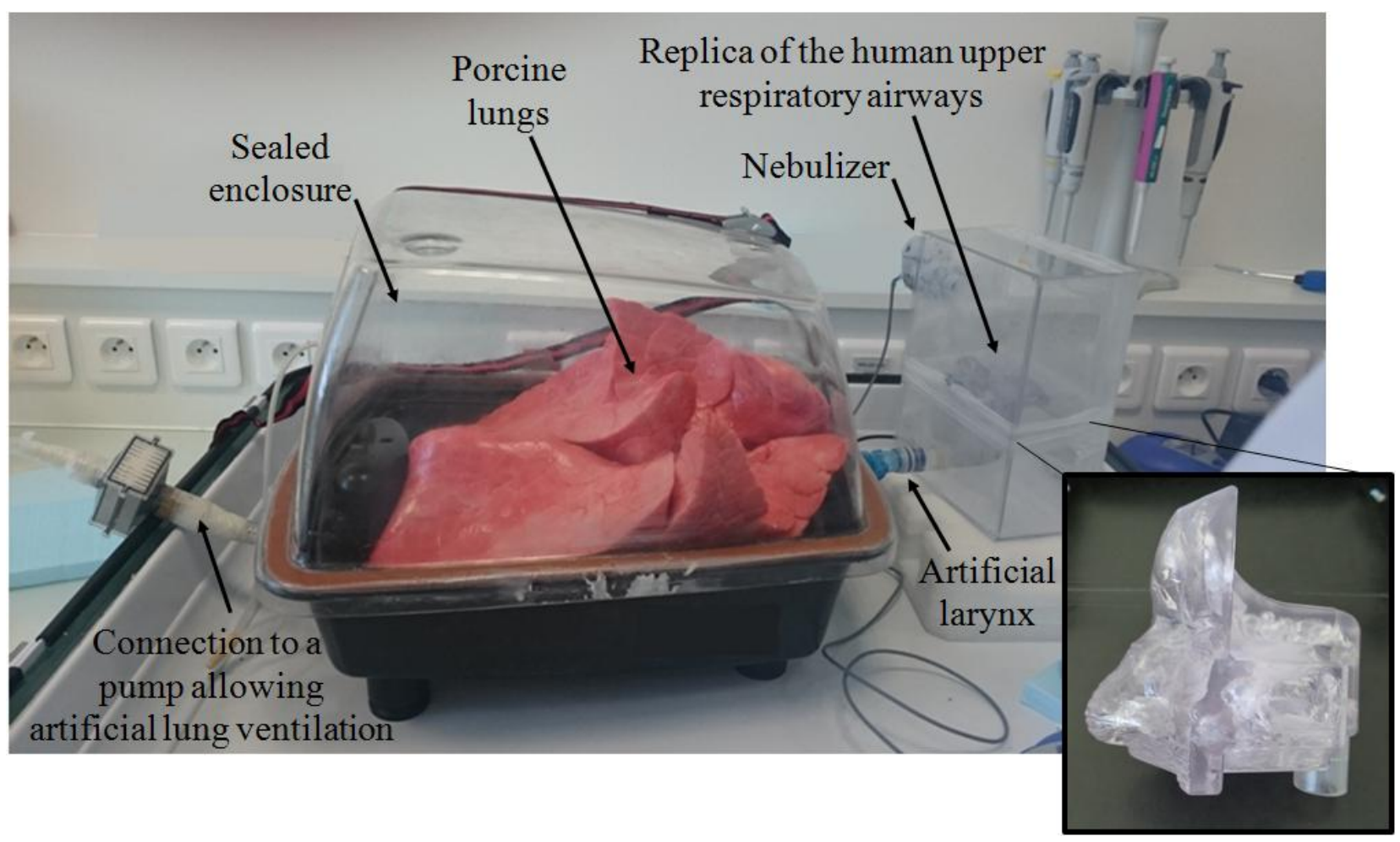


Figure 2

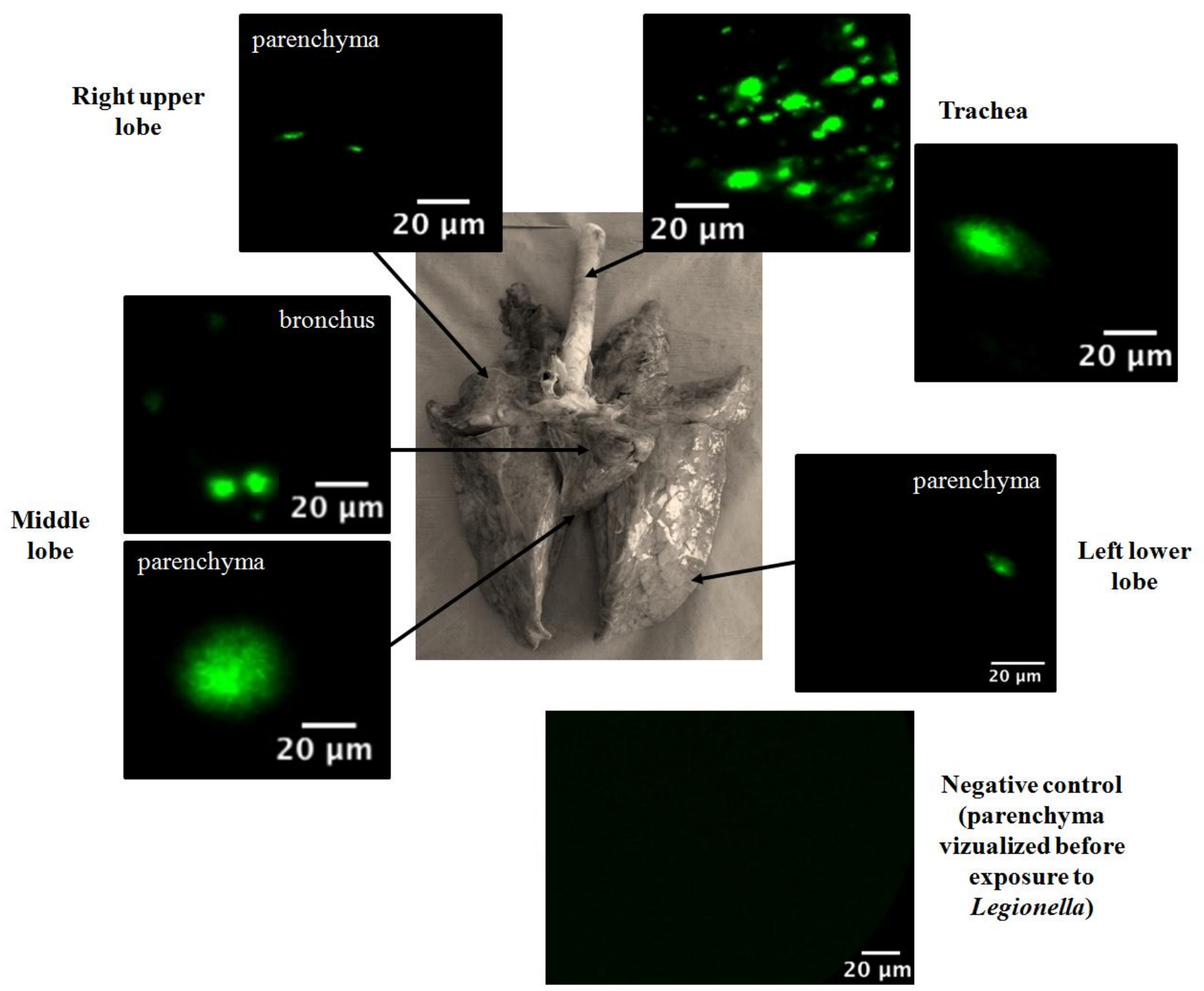


Figure 3

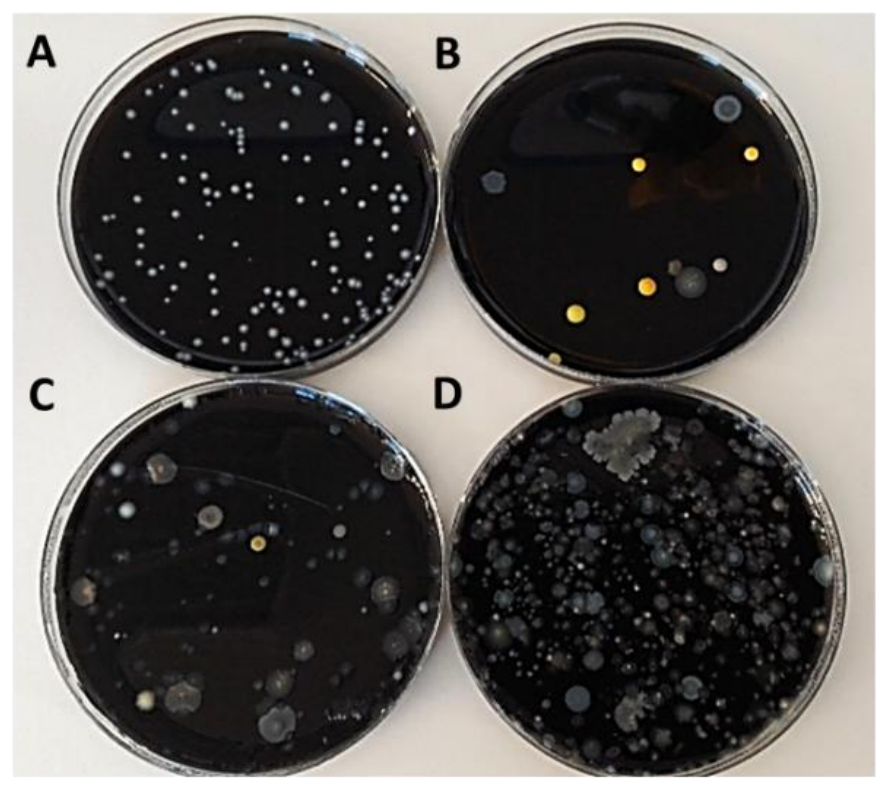


Figure 4

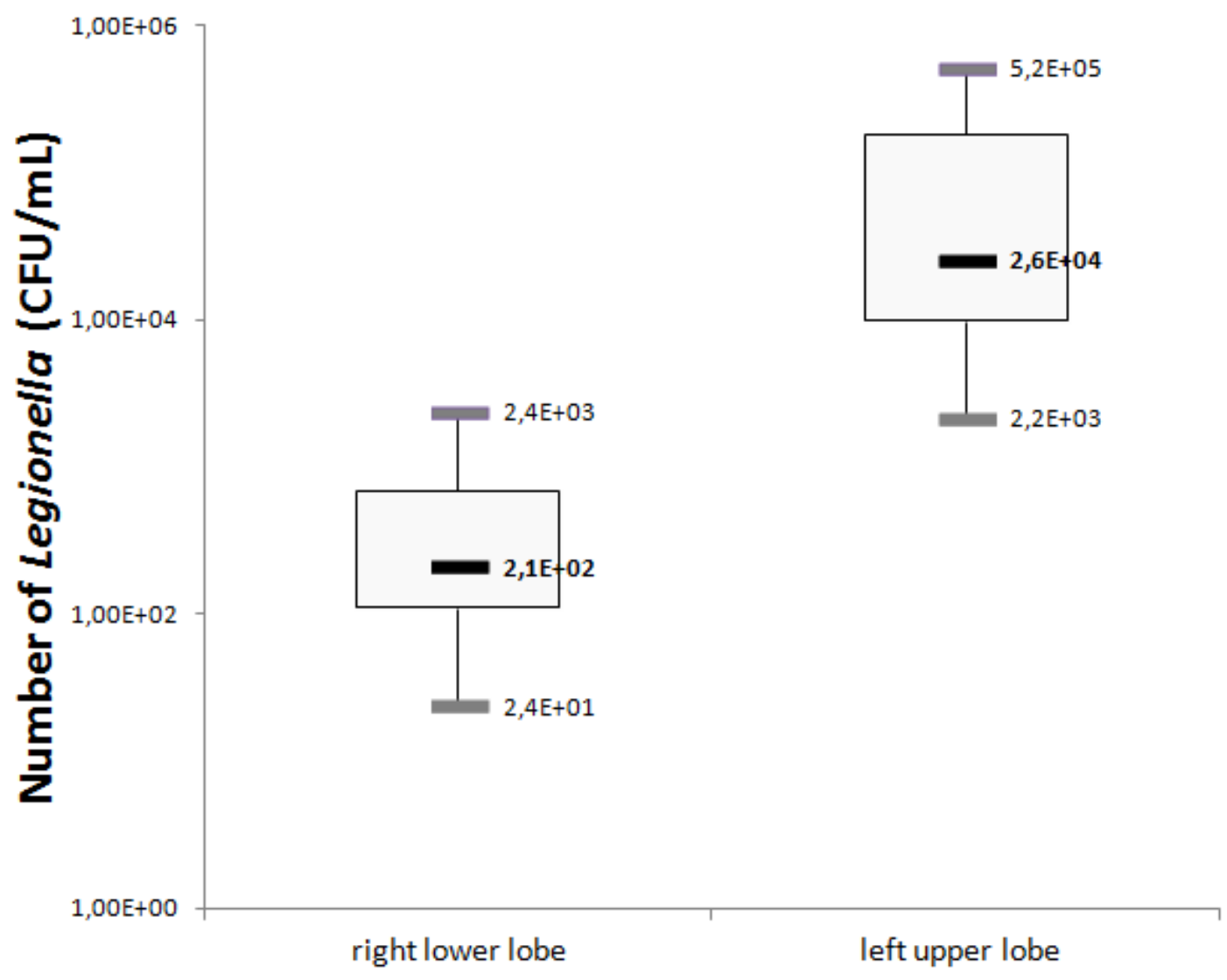

